EPJ Web of Conferences 110,01016 (2016)

DOI: $10.1051 /$ epjconf/201611001016

(C) Owned by the authors, published by EDP Sciences, 2016

\title{
DETERMINATION OF SECTIONAL CONSTANCY OF ORGANIC COAL-WATER FUEL COMPOSITIONS
}

\author{
Margarita A. Dmitrienko ${ }^{1}$, Galina S. Nyashina ${ }^{1, a}$, Pavel A. Strizhak ${ }^{1}$ \\ ${ }^{1}$ National Research Tomsk Polytechnic University, 634050 Tomsk, Russia
}

\begin{abstract}
To use widespreadly the waste of coals and oils processing in the great and the small-scale power generation, the key parameter, which is sectional constancy of promising organic coal-water fuels (OCWF), was studied. The compositions of OCWF from brown and bituminous coals, filter cakes, used motor, turbine and dielectrical oils, water-oil emulsion and special wetting agent (plasticizer) were investigated. Two modes of preparation were considered. They are with homogenizer and cavitator. It was established that the constancy did not exceed 5-7 days for the compositions of OCWF with brown coals, and 12-15 days for that compositions with bituminous coals and filter cakes. The injection of used oils in a composition of OCWF led to increase in viscosity of fuel compositions and their sectional constancy.
\end{abstract}

\section{Introduction}

In the first half of the XXI century it is predicted the enhancement of the role of coal in power engineering. This is due to its large reserves and sufficiently intensive depletion at oil and deposits. One way to increase the energy and resource efficiency of fuel technologies is applying the water-coal fuels (WCF). Technology adoption for preparing and combusting the WCF empowers to involve the tens of million tons of coal sludge in a power supply of countries, this sludge can be one of components of coal-water suspensions [1]. Also non-power brown coals, solid residual refinement products of coal, oil and a lot of other things can be a combustible base of suspended fuel.

The main problems towards the widespread application of WCF are low measure of the constancy of the main technological characteristics, high ash level of feedstock, sufficiently low efficiency of the known reagents as plasticizers and stabilizers [2]. The viscosity and constancy of water-coal dispersivities (suspensions) are the important technical characteristics of CWF which provide the optimal conditions for its transportation and burning. The works [2,3] describe the experimental investigations in determining the constancy of water-coal suspensions with adding different kinds of plasticizers as mazut, sodium humate, carboxymethylcellulose and lignosulphonate. It was established in $[2,3]$ that the constancy of suspensions with adding carboxymethylcellulose and lignosulphonate does not exceed 20 days [1], with mazut not more than 10 days [2]. Applying the sodium humate as a reagent-plasticizer allowed producing the coal-water suspensions with spatial reticulatus pattern which is not broken down during 30 days [2].

The tons of industrial and energetical waste is produced every year in Russia. They are used oils of different power plants, motors, turbines, transformers, oil slugs and measures forming at purification of oil pipelines, fucy, polymers after oil reclaiming, , coal-tar pitch, filter cokes of coal-preparation plants which can be used for a fuel preparation too. One direction to determine the technologies of using CWF is producing organic coal-water fuel (OCWF) compositions $[4,5]$. It is, in the preparation of such suspensions the application of the above waste is appropriate, as plasticizer additions. At the moment the lack of experimental and theoretical framework does not allow drawing definitive conclusions about the characteristics of segmental stability of various compositions of OCWF. It is interesting to determine experimentally the integral characteristics of segmental stability of OCWF at various compositions and different ways of their preparation.

The aim of the work is to determine experimentally the integral characteristics of segmental stability of advanced organic coalwater fuels at various compositions and different ways of their preparation.

\section{Experimental procedure}

To produce liquid composite fuel, two procedures using MPW-324 and ball-tube mill (analogue of traditional cavitator) were developed.

\footnotetext{
a Corresponding author: gsn1@tpu.ru
} 


\section{EPJ Web of Conferences}

In the first stage, for a procedure using homogenizer, the oil-water emulsion was prepared. Components were weighted by analytical balance ViBRA HT 84RCE, then they were added into a vessel of homogenizer (volume 0.251 ) for mixing, the duration of which was 3 minutes. After that coal dust or filter cake (according to required relative mass concentration) was injected into a vessel with emulsion and mixed during 10 minutes again. Prepared samples in a volume of 0.251 were placed in glass vessels of corresponding volume.

We prepared OCWF by ball-tube mill included two-liter ceramic drum, grinding bodies of the same material and specialty rolls in several stages too. Before conducting the milling process, the coal dust, distillied water and grinding bodies were weighted. Then, weighted coal and balls were filled into a drum (correlation between coal and balls for homogeneization with additional mechanical effect is 1:1) and after that water was poured. Drum head was tightened securely with fixing bolt for reliable pressurization. Further, the drum was placed on the rolls. $10 \%$ of used oil and $10 \%$ of additional water necessary for increasing the flow characteristics of initial fuel (initial viscosity was unsuitable for further grinding) was added to initial filter cake (moist one as received from dressing mill) of mass 500 gram. Then, grinding bodies were thrown in correlation 1:1 and the drum milled them during the 2 hours.

The mechanical effect of grinding bodies on samples is the main difference in methods with using a mill and homogenizer, that led to varying their rheological behavior and ignition characteristics (due to decrease of particle sizes).

We investigated three typical filter cakes - waste of coal processing at dressing mills in Kemerove region, Russia: "Severnaya" (bituminous coal), "Chernigovskaya-Koksovaya" (low-caking coal), "Kaltanskaya-Energeticheskaya" (nonbaking coal). As liquid combustible component of OCWF we applied compositions based on used motor, turbine and transformer oils and petrolium.

In experiments for determining characteristics of sectional stability by samples, the mixtures of different filter cake ranks with used oils and petroleum were applied:

- $\quad 100 \%$ filter cake from nonbaking coal (homogenizer);

- $\quad 100 \%$ filter cake from bituminous coal (homogenizer);

- $\quad 100 \%$ filter cake from low-caking coal (homogenizer);

- $\quad 90 \%$ filter cake from bituminous coal $+10 \%$ turbine oil (homogenizer);

- $\quad 90 \%$ filter cake from bituminous coal $+10 \%$ transformer oil (homogenizer);

- $\quad 90 \%$ filter cake from bituminous coal $+10 \%$ motor oil (homogenizer);

- $\quad 90 \%$ filter cake from bituminous coal $+10 \%$ motor oil (cavitator);

- $\quad 90 \%$ filter cake from bituminous coal $+10 \%$ turbine oil (cavitator);

- $\quad 90 \%$ filter cake from bituminous coal $+10 \%$ transformer oil (cavitator);

- $\quad 90 \%$ filter cake from bituminous coal $+10 \%$ petroleum from Gerasimovskoe field $\rho=867 \mathrm{~kg} / \mathrm{m}^{3}$ (homogenizer);

- $\quad 90 \%$ filter cake from bituminous coal $+10 \%$ oiled mixture (homogenizer);

- $\quad 90 \%$ filter cake from bituminous coal $+10 \%$ turbine oil with mechanical admixtures (homogenizer).

Evaluation of segmental stability of the fuel suspension was determined by the disintegration method which consists in measuring the bed volume of time ligament detached from the basic mass on keeping and transportation.

We observed the disintegration process of samples by measuring cylinders of $50 \mathrm{ml}$ volume graduated in $1 \mathrm{ml}$ and $25 \mathrm{sm}^{3}$ graduated in $1 \mathrm{sm}^{3}$.

Research samples were filled into measuring cylinders of $50 \mathrm{ml}$ volume (samples No.1, No. 2) and $15 \mathrm{sm}^{3}$ (all other samples). For example, Fig. 1 illustrates the research OCWF compositions of filter cake from bituminous coal with $10 \%$ turbine, transformer and motor oils, obtained by homogenizer, correspondingly.

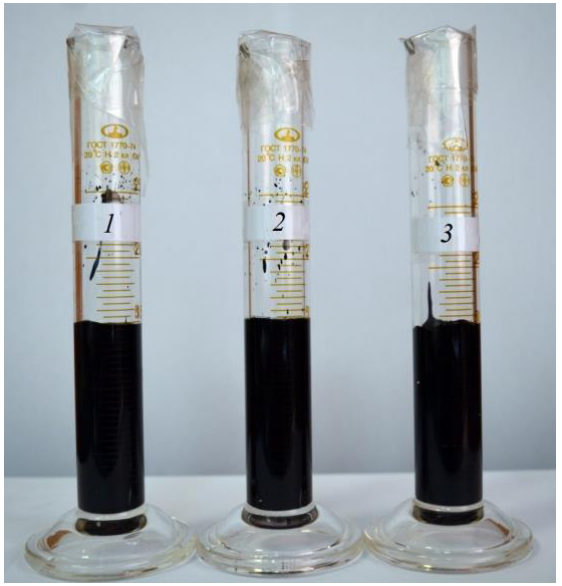

Figure 1. Appearance of vessels with various OCWF compositions: $1-90 \%$ filter cake from bituminous coal $+10 \%$ turbine oil, $2-90 \%$ filter cake from bituminous coal $+10 \%$ transformer oil, $3-90 \%$ filter cake from bituminous coal $+10 \%$ motor oil. 
After 1 hour we measured the volume of separated (more transparent) ligament (Fig. 2). Consistency index $\mathrm{Y}_{1}$ was calculated by the formula:

$$
Y_{1}=\frac{V_{0}}{V_{c}},
$$

where $V_{0}, V_{\mathrm{c}}$ is the volume of composition poured into a cylinder and a volume of ligament separated as time passed, correspondingly.

Figure 2 presents an appearance of experimental samples with the formation of separated ligament on OCWF surface, these samples were obtained by homogenizer (1) and cavitator (2).

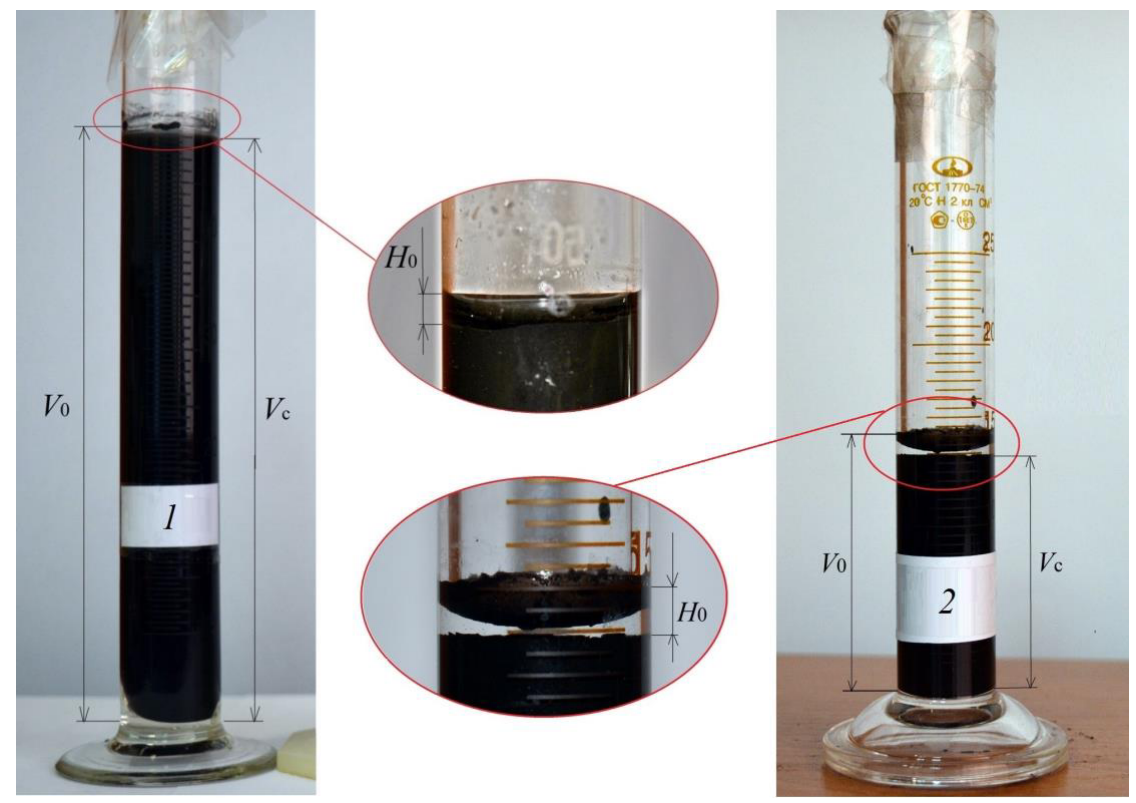

Figure 2. Presentation of typical disintegration after 15 days: $1-100 \%$ filter cake from nonbaking coal (homogenizer), $2-90 \%$ filter cake from nonbaking coal $+10 \%$ transformer oil (cavitator).

\section{Results and discussion}

Resulting from conducted experimental investigations, periods of sectional stability persistence of prepared OCWF were determined by homogenizer and cavitator. We obtained characteristic curves, which presented in Fig. 3-5.

Fig. 3, 4 illustrate experimental dependences of disintegration thickness values on the observation time (in days). 


\section{EPJ Web of Conferences}

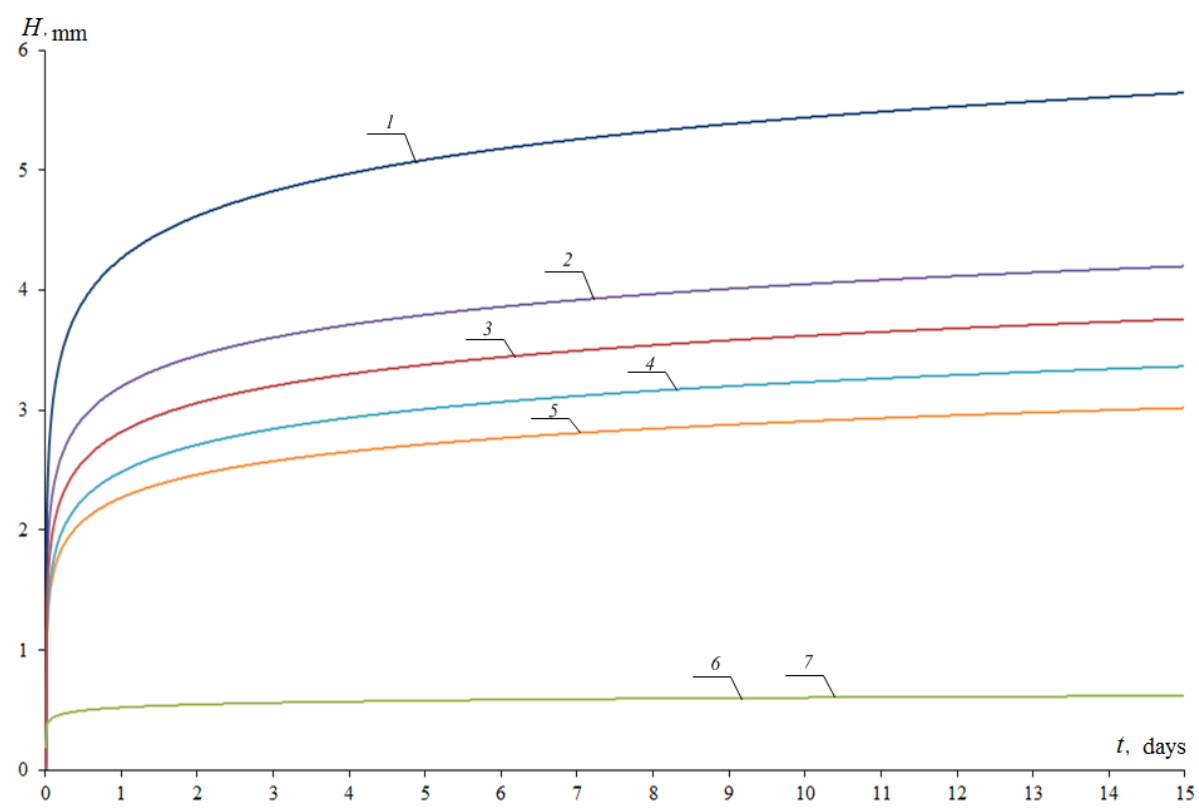

Figure 3. Experimental values of disintegration thickness: $1-100 \%$ filter cake from nonbaking coal, test tube No. 1 (homogenizer); $2-90 \%$ filter cake from bituminous coal $+10 \%$ transformer oil (cavitator); $3-100 \%$ filter cake from nonbaking coal, test tube No. 2 (homogenizer); 4 $-90 \%$ filter cake from bituminous coal $+10 \%$ turbine oil (cavitator); $5-90 \%$ filter cake from bituminous coal $+10 \%$ motor oil (cavitator); 6 - $100 \%$ filter cake from low-caking coal (homogenizer); $7-100 \%$ filter cake from bituminous coal (homogenizer).

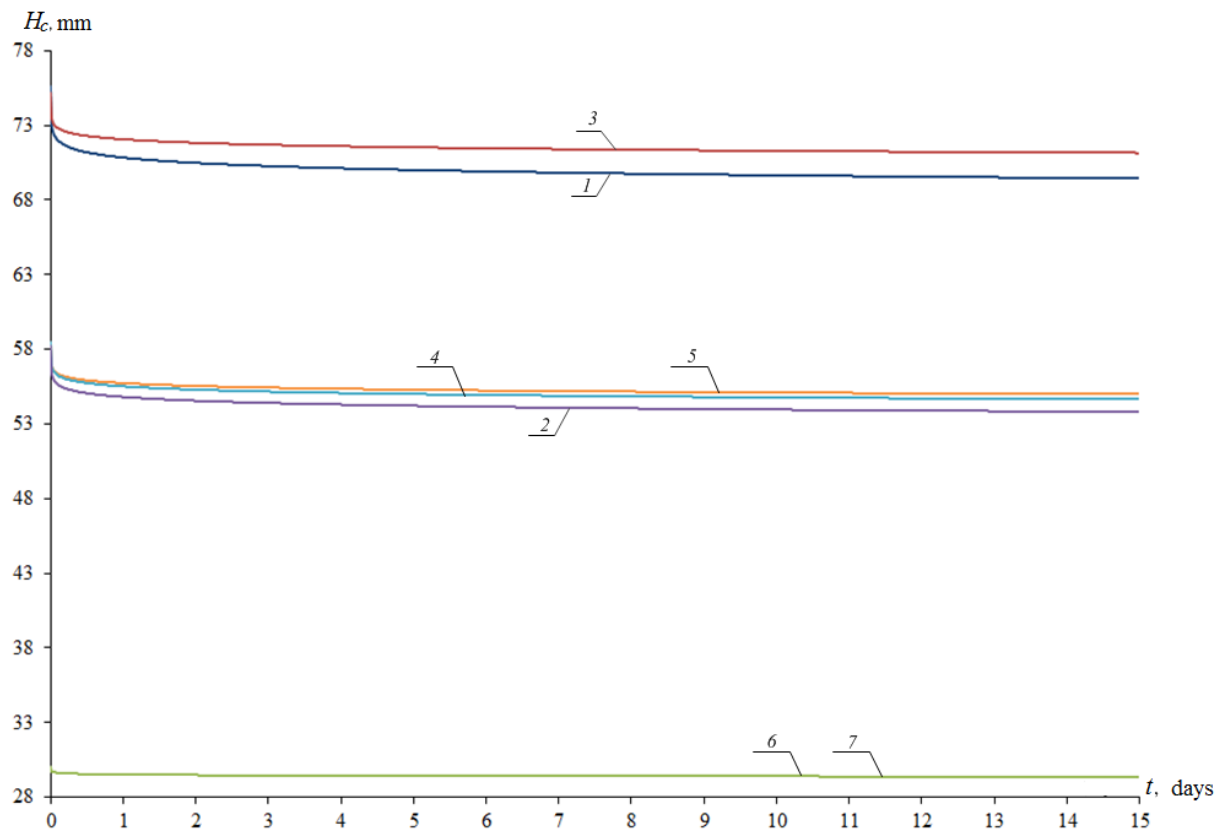

Figure 4. Experimental values of disintegration thickness: $1-100 \%$ filter cake from nonbaking coal, test tube No. 1 (homogenizer); $2-90 \%$ filter cake from bituminous coal $+10 \%$ transformer oil (cavitator); $3-100 \%$ filter cake from nonbaking coal, test tube No. 2 (homogenizer); 4 $-90 \%$ filter cake from bituminous coal $+10 \%$ turbine oil (cavitator); $5-90 \%$ filter cake from bituminous coal $+10 \%$ motor oil (cavitator); 6 - $100 \%$ filter cake from low-caking coal (homogenizer); 7 - $100 \%$ filter cake from bituminous coal (homogenizer).

As it can be seen from Figures 3 and 4, filter cake from nonbaking coal produced according to the procedure using a homogenizer has the smallest sectional stability. These compositions are disintegrated in a short time (up to 4 days), what forms 
water ligament on a CWF surface. Finally, this makes its using difficult as a stable fuel. Filter cake from bituminous and lowcaking coal were disintegrated too. However,thickness of formed ligament is significantly lower than for filter cake from nonbaking coal. Suspensions produced in the way usnig homogenizer and adding agents constituting used motor, transformer, turbine oils, petrolium, oiled mixture were found sufficiently consistent, aggregative stable and did not disintegrated during 15 days.

In assessing segmental, aggregate and rheological characteristics of OCWF prepared using cavitator, we can note the following. Fuel, prepared by this method has no stable rheological properties. Quite an active disintegration of samples started after one day after preparation.

According to review of publications [1-7] we carried out a comparative analysis of known reagents-plasticizers with that one considered in the present work (based on used motor, turbine and transformer oils).

It was investigated the influence of following reagents: mazut $2 \%$, sodium humate $2 \%$, carboxymethylcellulose (CMC) $1 \%$, lignosulfonate (LSN) $1 \%$. The efficacy of these additives is due to their physico-chemical properties, specialty of their structure, consisting of hydrocarbon, aromatic, carboxylic, hydroxyl, and other groups.

We judged on stability of coal-water suspensions by the height of the layer of the precipitating dispersed phase and a change in technical characteristics over time. All experimental and analytical data are shown in Figure 5.

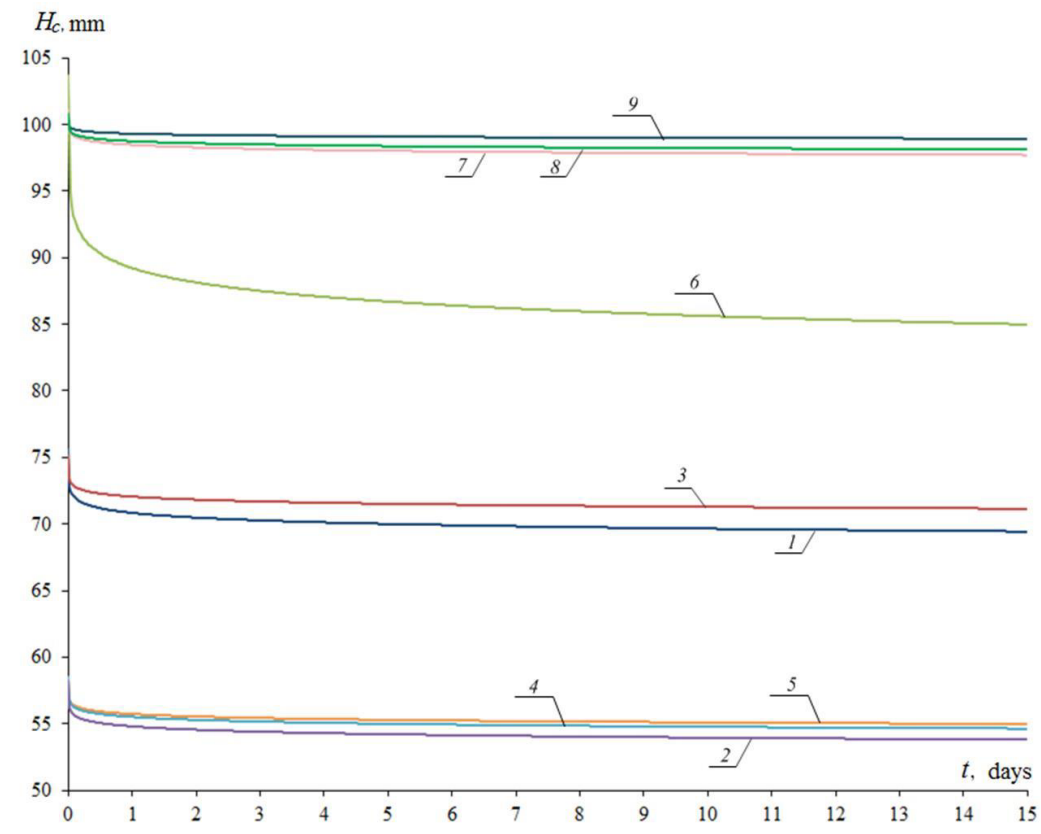

Figure 5. Numerical characteristics of OCWF stability: $1-100 \%$ filter cake from nonbaking coal, test tube No. $1 ; 2-90 \%$ filter cake from bituminous coal $+10 \%$ transformet oil; $3-100 \%$ filter cake from nonbaking coal, test tube No. $2 ; 4-90 \%$ filter cake from bituminous coal + $10 \%$ turbine oil; $5-90 \%$ filter cake from bituminous coal $+10 \%$ motor oil; $6-\mathrm{BVT}+2 \%$ mazut [2]; $7-\mathrm{CWF}+2 \%$ sodium humate [2]; $8-$ CWF $+1 \% \operatorname{LST}[1] ; 9-\mathrm{CWF}+1 \% \mathrm{KMC}[1]$.

Obtained experimental data correlate well with data from [2-10]. Type of the dependence determined in experiments is similar to that one presented in [2-10]. Thus, in addition to the already known plasticizers, it is appropriate to apply as stabilizers the waste of petroleum-derived products, as well as oil refining, chemical and energy industries.

\section{Conclusions}

- While experimentations the values of limited (maximal) durations of preserving the sectional stability of OCWF compositions - 15 days. It is established that it is expedient to use cheap and affordable waste (used oils of various power plants, turbines, motors, transformers, oil slugs and measures forming in the purification of pipelines and reservoirs, fusy, polymers after oil regeneration, coal-tar pitches) in obtaining coal-water suspensions as plasticizing agents. This will simplify and reduce the cost of the whole process of preparing OCWF.

- Studied in this paper, methods of creating coal-water compositions (with homogeneity and cavitator) lead to the conclusion that regardless of the component composition of suspension, its preparation with cavitator leads to more disintegra- 


\section{EPJ Web of Conferences}

tion (separation of water ligament). Probably, this is due to the additional grinding of coal in the case of cavitator and a decrease in viscosity of OCWF.

- It is established that the stability of coal-water suspensions obtained basing concentrates is determined by physical and chemical properties of additions. The injection into a composition of combustible liquid allows obtaining a suspension with a relatively high stability of the rheological characteristics, segmental and aggregate stability. The experimental data allow us to expand the current understanding of composite fuel coal-water suspensions.

This work supported by the Russian Science Foundation, project 15-19-10003.

\section{References}

1. K.N. Trubetskoi, A.S. Kondrat'ev, V.I. Murko, V.E. Zaidenvarg, G.A. Kassikhin, I.K. Nekhoroshii,Thermal engineering. 55 (5), 413 (2014)

2. S.N. D'yakov, A.V. Papin, A.V. Nevedrov, E.V. Zhbyr', Coke and Chemistry, 55 (10), 363 (2012)

3. G.A. Solodov, E.V. Zhbyr, A.V. Papin, A.V. Nevedrov, Bulletin of the TPU, 310 (1), 129, (2007)

4. Y. Tu, Z. Xu, W. Wang, Powder Technol., 281, 121 (2015)

5. W.Gajewski, A. Kijo-Kleczkowska, J.Leszczynski, Fuel, 88, 221 (2009)

6. J. Zhu, G. Zhang, G. Liu, Q. Qu, Y. Li, Fuel Process. Technol., 118, 187 (2014)

7. M. P. Baranova, T. A. Kulagina, S.V. Lebedev, Chem. Pet. Eng., 45 (9-10), 554 (2009)

8. A.I. Borzov, M.P. Baranova, Solid Fuel Chem., 40 (4), 36 (2006)

9. J.-H. Wu, J.-Z. Liu, Y.-J. Yu, R.-K. Wang, J.-H. Zhou, K.-F. Cen, Pet. Sci., 12 (1), 157(2015)

10. A. Staroń, Z. Kowalski, M. Banach, Analysis of the process of coal micronization conducted in order to obtain coal-water liquids (Proceedings of the 8th International Conference on Mechanochemistry and Mechanical Alloying, INCOME 2014) 